\title{
Compras públicas sustentáveis: Uma análise dos editais de licitação de cidades brasileiras participantes do Programa Cidades Sustentáveis*
}

\author{
Contratación pública sostenible: un análisis de los pliegos de licitación de las ciudades brasileñas que participan \\ en el Programa de Ciudades Sostenibles \\ Sustainable public procurement: An analysis of the tender documents of Brazilian cities participating in the \\ Sustainable Cities Program
}

Livia Vilar Lemos ${ }^{\text {a }}$

Universidade de Pernambuco, Brasil

DOI: https://doi.org/10.11144/Javeriana.cc21.cpsa

livia.lemos@upe.br

ORCID: https://orcid.org/0000-0003-1506-3840

Recepção: 25 Março 2020

Raimundo Nonato Rodrigues

Aprovação: 29 Setembro 2020

Universidade Federal de Pernambuco, Brasil

Publicação: 18 Dezembro 2020

ORCID: https://orcid.org/0000-0003-0505-4369

Umbelina Cravo Teixeira Lagioia

Universidade Federal de Pernambuco, Brasil

ORCID: https://orcid.org/0000-0001-8422-7808

Jeronymo José Libonati

Universidade Federal de Pernambuco, Brasil

ORCID: https://orcid.org/0000-0001-9164-9144

\section{Resumo:}

O objetivo dessa pesquisa é identificar critérios de sustentabilidade (ambiental e social) presentes nos editais de licitação de três municípios brasileiros de pequeno porte das regiões Sudeste e Sul, participantes voluntários do Projeto Cidades Sustentáveis (PCS). O parâmetro de seleção desses municípios, além da participação do PCS, é ter adotado o indicador Compras Públicas Sustentáveis (CPS) como parte do seu plano de metas do projeto. O período de elaboração da pesquisa foi de 2018 a 2019. Foram coletados e analisados 43 editais publicados em 2018. A coleta de dados nos editais de licitação foi realizada por Análise de Conteúdo (AC). Foi executada uma pesquisa bibliográfica para a construção do sistema de critérios e categorias da AC, que possibilitou a coleta e ordenação das informações obtidas. Ao realizar a análise dos dados baseada na quantidade de critérios sustentáveis identificados, verificou-se que esses editais contemplam critérios sociais e ambientais de sustentabilidade, sendo os sociais mais presentes e a maior parte deles em decorrência de prerrogativa legal de apoio as microempresas e empresas de pequeno porte.

Códigos JEL: H57, R58, Q56.

Palavras-chave: Gestão pública, compras públicas sustentáveis, sustentabilidade ambiental, sustentabilidade social, Programa Cidades Sustentáveis.

\section{Resumen:}

El objetivo de esta investigación es identificar criterios de sostenibilidad (ambiental y social) presentes en los pliegos de licitación de tres pequeños municipios brasileños de las regiones Sudeste y Sur, participantes voluntarios del Proyecto Ciudades Sostenibles (PCS). El parámetro para la selección de estos municipios, además de la participación en el PCS, es haber adoptado el indicador de Compras Públicas Sostenibles (CPS) como parte de su plan de metas del proyecto. El período de elaboración de la investigación fue de 2018 a 2019. Se recolectaron y analizaron 43 convocatorias a licitación publicadas en 2018. La recolección de datos en los pliegos de licitación fue realizada por Análisis de Contenido (AC). Se realizó una búsqueda bibliográfica para construir el sistema de criterios y categorías del AC, que permitió recolectar y ordenar la información obtenida. Al realizar el análisis de datos con base en la cantidad de criterios de sostenibilidad identificados, se encontró que estos pliegos incluyen criterios sociales y ambientales de sostenibilidad, siendo los sociales los más presentes y la mayoría de ellos por la prerrogativa legal de apoyo a las micro y pequeñas empresas.

\section{Autor notes}

a Autor de correspondência. E-mail: livia.lemos@upe.br 
Códigos JEL: H57, R58, Q56.

Palabras clave: Gestión pública, contratación pública sostenible, sostenibilidad social, sostenibilidad del medio ambiente, Programa de Ciudades Sostenibles.

\begin{abstract}
:
The aim of the research is to identify sustainability criteria (environmental and social) present in the tender documents of three small Brazilian municipalities in the Southeast and South regions, voluntary participants in the Sustainable Cities Project (PCS, in its Portuguese initials). The parameter for selecting these municipalities, in addition to the participation of the PCS, is having adopted the Sustainable Public Procurement (CPS, in its Portuguese initials) indicator as part of their project goals plan. The period of elaboration of the research was from 2018 to 2019. 43 invitations to tender published in 2018 were collected and analyzed. The data collection in the tender documents was carried out by Content Analysis (CA). A bibliographic research was performed to build the system of criteria and categories of the CA, which made it possible to collect and order the information obtained. When performing the data analysis based on the number of sustainable criteria identified, it was found that these documents include social and environmental sustainability criteria, with the social ones most present and most of those them due to the legal prerogative of support to micro and small companies.
\end{abstract}

JEL Codes: H57, R58, Q56.

Keywords: Public administration, sustainable public procurement, social sustainability, environmental sustainability, Sustainable Cities Program.

\title{
Introdução
}

Em 1987, o conceito de sustentabilidade surgiu a partir de uma reflexão sobre os padrões de consumo e de utilização dos recursos naturais na produção ocorridos à época. Consequentemente, difunde-se a concepção de desenvolvimento sustentável que consiste em buscar, a partir de um processo político, harmonizar a necessidade de consumo da geração presente com a possibilidade de as gerações vindouras continuarem a ter os recursos disponíveis à sua sobrevivência. O desenvolvimento sustentável é estabelecido na busca pela harmonia entre a viabilidade econômica e a sustentabilidade social e ambiental - conhecido como tripé da sustentabilidade (Gomes \& Zambam, 2011; Reis \& Backes, 2015). Nesse sentido, há uma articulação para o engajamento de todos os setores da sociedade em torno desse objetivo e, por sua vez, a atuação estatal é estabelecida na realização de políticas públicas que visem a promoção da sustentabilidade, considerando o tripé anteriormente citado (Reis \& Backes, 2015).

O estado como agente promotor da sustentabilidade atua como ofertante de serviços, legislador, promotor de políticas públicas e consumidor. O último aspecto se alicerça ao realizar exigências e estabelecer requisitos em suas compras de acordo com o tripé da sustentabilidade (Biderman, Macedo, Neto et al., 2008; PachecoBlanco \& Bastante-Ceca, 2016; Souza et al., 2015), com o propósito de promover "vantagem econômica, social e ambiental para a sociedade" (Alarcão, Tupinambá, Stefani et al., 2018, p. 94). Assim, espera-se impactar a estrutura do mercado com um efeito cascata ao influenciar as cadeias produtivas a se tornarem sustentáveis. E isso ocorre pela própria iniciativa privada com o fim de se tornar um potencial fornecedor aos entes públicos (Bratt, Hallstedt, Robèrt et al., 2013; Oliveira \& Luzio dos Santos, 2015; Testa, Annunziata, Iraldo \& Frey, 2016).

No Brasil, a Lei No 8.666/93 disciplina o processo administrativo das compras e vendas feitas por todos os entes federativos, denominado de licitação. Entre 1990 a 2010, o governo federal brasileiro executou diversas ações em nível nacional sobre sustentabilidade. Uma dessas ações foi a atualização da Lei No 8.666/93, em 2010, para incluir o desenvolvimento nacional sustentável como uma das finalidades da licitação pública (Lei No 8.666/93; Oliveira \& Luzio dos Santos, 2015; Reis \& Backes, 2015). Deste modo, admite-se o uso da compra pública como promotora da sustentabilidade quando são estipulados critérios sustentáveis para a escolha do futuro fornecedor. Esse tipo de compra ficou conhecido com as compras públicas sustentáveis, doravante CPS. 
Com a alteração dessa lei, o governo federal brasileiro estabeleceu uma medida não facultativa para os entes públicos. No entanto, existem programas, realizados por órgãos públicos ou por organizações da sociedade civil, que buscam a adesão voluntária dos governantes. Um desses é o Projeto Cidades Sustentáveis, que foi implementado no Brasil em 2012 e é uma agenda de sustentabilidade urbana que atua na sensibilização de governos municipais. Com isso, busca-se a aplicação de um conjunto de políticas públicas que visem transformar as cidades em locais mais justos e sustentáveis (PCS, 2019b). O projeto consiste na oferta de uma agenda de metas e indicadores sustentáveis para os municípios. Um dos indicadores é o de Compras Públicas Sustentáveis, que calcula a proporção de compras públicas sustentáveis no total das compras públicas realizadas pela prefeitura anualmente (PCS, 2019a).

Considerando esse contexto, o objetivo geral desse trabalho é o de identificar a presença de critérios de sustentabilidade ambiental e social nos editais de licitação dos municípios que atendem a meta Compras Públicas Sustentáveis ao participarem do Projeto Cidades Sustentáveis. Os passos seguintes consistem na identificação dos municípios participantes do projeto que se enquadram no critério estipulado para a composição da amostra; posteriormente, na coleta dos editais a serem analisados segundo os critérios determinados por modalidade e objeto de licitação; por fim, com os editais coletados, na leitura em busca da presença dos critérios de sustentabilidade ambiental e social presentes.

Espera-se que os resultados da pesquisa possam contribuir trazendo evidências do emprego de critérios de sustentabilidade social e ambiental presentes nos editais, tanto para gestores públicos quanto para os potenciais fornecedores. A compreensão dos critérios utilizados pelos municípios evidencia ao mercado privado quais dos norteadores de sustentabilidade são prioritários para a gestão pública (Igarashi, de Boer, \& Michelsen, 2015).

Também há uma contribuição à literatura, pois estudos realizados com órgãos públicos brasileiros trataram sobre os ganhos de escala nas compras públicas sustentáveis compartilhadas em âmbito estadual (Silva \& Barki, 2014), identificaram evidências em órgãos federais (Carvalho \& Sousa, 2013; Gallon, Flores, Trevisan, \& Kneipp, 2019) e a experiência em alguns estados brasileiros da região Sul e Sudeste (Oliveira \& Luzio dos Santos, 2015), contudo, não foram identificadas evidências suficientes sobre a experiência dos municípios participantes do Projeto Cidades Sustentáveis.

\section{Referencial teórico}

\section{Compras Públicas Sustentáveis}

As compras públicas referem-se às compras realizadas pelo poder público de bens ou serviços nas quais há uma relação contratual entre o governo e o fornecedor que está participando do processo de oferta de serviços públicos (Ribeiro \& Inácio Júnior, 2019). As compras governamentais possuem uma expressiva participação na economia dos países. Na Europa, "o mercado de contratos públicos é considerado o maior setor empresarial no mundo e representa 16\% do produto interno bruto da UE" (Grandia, 2016, p. 183). No Brasil, o peso das compras públicas alcança patamar semelhante. Ribeiro e Inácio Júnior (2014) retratam que em 2012 as compras governamentais representavam 14,5\% do Produto Interno Bruto -PIB- do país. Dados mais recentes indicam que a média do mercado de compras públicas no Brasil, para o período de 2006 a 2016, representa $12,5 \%$ do PIB brasileiro (Ribeiro \& Inácio Júnior, 2019).

A relevância das compras governamentais não é fundamentada somente na sua representação em relação ao PIB. Essas aquisições são realizadas em decorrência de uma política pública previamente traçada, com objetivos delimitados que podem almejar “a obtenção de eficiência, a geração de emprego e o desenvolvimento local” (Ribeiro \& Inácio Júnior, 2019, p. 7). Dessa forma, ao depender da política pública estabelecida pelos governos, as compras governamentais podem prover a sociedade com outros ganhos, sendo usadas "como uma 
ferramenta para a promoção de indústrias específicas, desenvolvimento científico e tecnológicos, e promoção de bem-estar social, entre outros objetivos" (Ribeiro \& Inácio Júnior, 2019, p. 7).

Nessa perspectiva, as compras governamentais podem ser empregadas para a promoção do desenvolvimento sustentável. A European Commission -EC- retrata que os contratos públicos com a finalidade de promover um melhor ambiente seguem um processo, promovido pela entidade pública, no qual a procura por bens e serviços considerará um menor impacto ambiental no seu ciclo de vida, quando comparados com outros processos que não consideram tais variáveis (EC, 2016). Por sua vez, o tripé da sustentabilidade pode ser identificado nas compras públicas quando o processo de contratação contempla critérios semelhantes a estes: promover o uso eficiente de recursos públicos só realizando compras quando necessárias no momento (critério econômico); selecionar produtos menos poluidores (critério ambiental) e garantir que não haja a exploração de mão de obra infantil na oferta do serviço ou no ciclo de produção do produto (critério social) (Majerník, Daneshjo, Chovancová, et al., 2015).

Alguns autores (Grandia, 2016; Testa et al., 2016) apontam que quando o poder público adota critérios de sustentabilidade nas suas compras, o governo causa impactos positivos que viabilizam um sistema de produção mais limpo. Esse impacto pode ocorrer por duas razões. A primeira é porque as empresas do mercado privado reconhecendo o poder de compra estatal e desejando serem futuras fornecedoras podem, por iniciativa própria, se ajustarem para atender aos critérios de sustentabilidade. A outra razão é que quando a gestão pública considera a sustentabilidade como premissa, serve de exemplo à sociedade como um todo (Igarashi et al., 2015).

Do ponto de vista do gestor público, para realizar uma compra ele necessita cumprir etapas de forma que conduza o processo dentro da legalidade. Para isso, é desejável que esse gestor seja educado e treinado de modo que conheça as especificações necessárias para realizar o processo corretamente (Gelderman, Ghijsen, \& Brugman, 2006). A concretização das CPS depende da utilização efetiva de critérios sustentáveis pelo gestor público nas características do item a ser adquirido. Isso gera um maior esforço por parte do gestor para o desempenho da atividade (Igarashi et al., 2015). Com o intuito de uniformizar os critérios a serem utilizados na CPS, desde 2008 a European Commission -EC- desenvolve diretrizes com critérios sustentáveis para serem aplicadas por todos os estados membros nas compras públicas. O propósito é evitar uma distorção no mercado e proporcionar uma redução dos custos operacionais dos entes e fornecedores para compras sustentáveis (EC, 2018).

Nessa abordagem, há pesquisas que buscam o entendimento das características de sustentabilidade utilizadas no processo de seleção dos fornecedores nas CPS (Alencastro, Silva, \& Lopes, 2014; Carvalho \& Sousa, 2013; Gallon et al., 2019; Oliveira \& Luzio dos Santos, 2015; Testa et al., 2016). Em uma análise de como a adição desses critérios interferem no processo de tomada de decisão dos compradores públicos, Igarashi, de Boer et al. (2015) identificaram que tais compradores buscam simplificar a seleção de fornecedores sustentáveis, uma vez que a adição desse parâmetro torna a tomada de decisão mais complexa. Por isso, o critério de menor custo de aquisição ainda é o majoritário nas compras públicas, como apontam evidências na Europa (Bratt et al., 2013) e no Brasil (Gallon et al., 2019).

\section{Compras Públicas Sustentáveis No Brasil}

As compras governamentais de bens no Brasil são realizadas por um processo denominado licitação. $\mathrm{O}$ Tribunal de Contas da União -TCU- define licitação como o "procedimento administrativo formal em que a Administração Pública convoca, por meio de condições estabelecidas em ato próprio (edital ou convite), empresas interessadas na apresentação de propostas para o oferecimento de bens e serviços" (T. de C. da U. Brasil, 2010, p. 19). A proposta vencedora é a que ofertar o item dentro dos parâmetros solicitados ao menor custo. 
A Lei No 8.666/1993 (Lei da Licitação) normatiza o processo de licitação para todas as esferas de governo no país. Esse normativo estabelece critérios quanto à modalidade da licitação, apresentando cinco tipos: concorrência, tomada de preços, convite, concurso e leilão. Já quanto ao tipo, o instrumento legal apresenta quatro diferentes abordagens: menor preço, melhor técnica, técnica e preço e, por último, o maior lance ou oferta no caso das vendas ou concessões públicas (Lei No 8.666/93). Em 2002, o pregão é instituído como nova modalidade. A sua finalidade é a aquisição de bens e itens comuns e por isso utiliza o menor preço como critério de julgamento e classificação das propostas (Lei $\left.N^{\circ} 10.520 / 2002\right)$. O emprego do pregão é bastante popular na administração pública como um todo (Carvalho \& Sousa, 2013; Fernandes \& de Oliveira, 2015).

Entre 1990 a 2010, o governo federal brasileiro executou ações em nível nacional sobre sustentabilidade mediante a emissão de decretos, criação e modificações de lei (Oliveira \& Luzio dos Santos, 2015). Uma das modificações foi a promulgação da Lei No 12.349/2010, que em 2010 alterou a Lei No 8.666/93 para incluir o desenvolvimento nacional sustentável como uma das finalidades da licitação pública, além das existentes: cumprimento do princípio constitucional da isonomia e seleção da proposta mais vantajosa para a administração (Brasil, 1993; Reis \& Backes, 2015).

Desde então, iniciativas são realizadas pelo governo federal brasileiro para promover e facilitar a adoção de critérios de sustentabilidade nas licitações públicas. Em 2010, o então Ministério do Planejamento, Orçamento e Gestão -MPOG- publicou a Instrução Normativa Nº1/2010 que dispõe sobre os critérios de sustentabilidade ambiental em aquisições e contratações. Esse normativo estipula os critérios de sustentabilidade ambiental que devem ser considerados para contratação de obras ou serviços de engenharia, relaciona aqueles que podem ser considerados na aquisição de bens e determina a aplicação de práticas sustentáveis específicas, quando couber, na contratação de serviços não relacionados à engenharia (Instrução Normativa $\mathrm{N}^{\mathrm{o}}$ 01/2010). O governo federal também desenvolveu o Sistema de Catalogação de Material da União -CATMAT-, disponibilizado no site Comprasnet, que possibilita a ação de consultar um banco de dados para identificação de materiais com a opção de realizar a pesquisa filtrando por itens sustentáveis. Esse sistema tem por objetivo auxiliar o gestor público na elaboração do edital de licitação, contribuindo para a redução de erros na especificação do objeto licitado (M. da E. BRASIL, 2020). Sobre o CATMAT, Alencastro et al. (2014, p. 228) identificaram "a inexistência de dados sobre os critérios sociais ou ambientais para servir de suporte para as CPSs que visam a contratação de serviços”.

A última proposta do governo federal apresentada neste trabalho é a Agenda Ambiental na Administração Pública-A3P-, programa de adoção voluntária destinado às esferas federal, estadual e municipal e aos poderes executivo, legislativo e judiciário. A A3P é promovida pelo Ministério do Meio Ambiente com o intuito de “estimular os órgãos públicos do país a implementarem práticas de sustentabilidade", sendo um dos seus eixos temáticos relacionado às licitações sustentáveis (M. do M. A. Brasil, 2020, parag. 1).

Apesar da Instrução Normativa No1/2010 e o CATMAT serem destinados à aplicação no âmbito do governo federal, ambos são instrumentos válidos para auxiliar o gestor de outras esferas na consideração de critérios sustentáveis nas aquisições governamentais. Existem diversos documentos com fim semelhante de outras esferas e instituições do setor público, alguns deles estão consolidados na Cartilha de Compras Sustentáveis Municipais pelo Serviço Brasileiro de Apoio às Micro e Pequenas Empresas -SEBRAE-, cuja intenção é fornecer ferramentas ao gestor público municipal sobre o processo de compras públicas sustentáveis (Santos Neto, 2017).

As orientações, os programas para uma gestão pública sustentável e as especificações de critérios claros são ferramentas poderosas para o administrador público utilizar o seu poder e conduzir a gestão de forma sustentável. 


\section{Programa Cidades Sustentáveis (PCS)}

Segundo a Organização das Nações Unidas -ONU-, a estimativa de crescimento acelerado da população urbana até o 2015 e a consequente necessidade de estruturar as cidades de forma sustentável foram umas das principais motivações para o nascimento do Programa Cidades Sustentáveis (PCS, 2019b). O programa é realizado pela Rede Nossa São Paulo -RNSP-, da Rede Social Brasileira por Cidades Justas e Sustentáveis, e o Instituto Ethos. Trata-se de uma iniciativa que visa fornecer ferramentas para contribuir com governos e sociedade civil com o emprego do desenvolvimento sustentável nas cidades do Brasil (PCS, 2019b).

A participação dos municípios no programa é voluntária. Por isso, são desenvolvidas campanhas para a adesão dos municípios, de candidatos a prefeitos, partidos políticos e eleitores (PCS, 2019a). Os municípios que aderem às Cidades Sustentáveis dispõem de uma agenda para a sustentabilidade com metas a serem atendidas, usufruem da visibilidade midiática e da troca de experiências entre cidades participantes (RNSP et al., 2012). No Relatório Anual do PCS consta que, entre 2013 a 2016, 287 munícipios integraram o programa. Contudo, em seu site constam 192 cidades como signatárias cujos prefeitos, que foram eleitos em 2016, assinaram a carta-compromisso (PCS, 2017, 2018c).

A agenda de sustentabilidade do PCS possui 12 eixos temáticos considerando o tripé da sustentabilidade, aspectos políticos e culturais. Tais eixos foram ajustados à realidade brasileira a partir dos "compromissos de Aalborg (Dinamarca), um pacto político com o desenvolvimento sustentável” (RNSP et al., 2012, p. 4).

Há, também, o objetivo de alinhar as cidades brasileiras aos compromissos do Brasil firmados nas conferências promovidas pela ONU. O programa contempla em sua agenda os Objetivos de Desenvolvimento Sustentável -ODS- aprovados pela ONU em 2015, com 260 indicadores. Os ODS são estruturados em 17 objetivos globais e em 169 metas com o propósito "de acabar com a pobreza até 2030 e promover universalmente a prosperidade econômica, o desenvolvimento social e a proteção ambiental” (PCS, 2017, p. 14).

Para elaborar o seu plano de metas, a gestão municipal pode escolher quais indicadores atenderá, mas a quantidade é determinada pelo programa de acordo com o tamanho da sua população. Provavelmente, é por essa razão que não se observa o mesmo indicador sendo reportado por todos os municípios aderentes ao programa.

Dentre os 12 eixos temáticos, o de interesse deste estudo é o de Gestão Local para a Sustentabilidade que contém doze metas com o objetivo de promover a prática de uma gestão local eficiente e que congregue procedimentos de planejamento, execução e avaliação (PCS, 2018a). O indicador Compras Públicas Sustentáveis é o estudado desse eixo, que reporta o percentual de compras públicas sustentáveis no total de compras públicas por município a cada ano. O objetivo é garantir que o município utilize o seu poder de compra para promover o desenvolvimento sustentável local (PCS, 2018b).

Em uma consulta realizada no site do PCS em agosto de 2018, foram identificados os municípios brasileiros que consideravam a meta CPS nos seus respectivos planos do Programa Cidades Sustentáveis. Nessa época, alguns dos municípios que tinham a referida meta como componente do seu planejamento não reportavam os resultados alcançados com assiduidade e forneciam pouca ou nenhuma justificativa sobre o não atendimento. Os dados daqueles que apresentaram os resultados são expostos na tabela 1. 
TABELA 1

Meta Compras Públicas Sustentáveis por município

\begin{tabular}{|c|c|c|c|c|c|c|c|c|c|}
\hline \multirow{2}{*}{ UF } & \multirow{2}{*}{ Cidade } & \multicolumn{8}{|c|}{ CPS por ano $(\%)$} \\
\hline & & 2010 & 2011 & 2012 & 2013 & 2014 & 2015 & 2016 & 2017 \\
\hline \multirow{2}{*}{ MG } & Belo Oriente & & & & & & & 0,1 & \\
\hline & Ipatinga & & & & & & & 1,2 & \\
\hline & Barueri & & & & 4,3 & 1,7 & 4,1 & & \\
\hline \multirow[t]{6}{*}{ SP } & Campinas & 0,01 & 0,2 & 0,6 & 0,1 & 0,2 & 0,4 & & \\
\hline & Guaira & & & & & & & & 0,1 \\
\hline & Guarujá & & & & & & 100 & & \\
\hline & Itatiba & & & 8,4 & & & & & \\
\hline & Jaguariúna & & & & & & & 9,4 & 12,1 \\
\hline & Santos & 0,1 & 0,2 & 0,2 & 0,5 & 0,4 & 0,4 & 0,01 & \\
\hline \multirow{4}{*}{ PR } & Céu Azul & & & 0,5 & & & & & \\
\hline & Entre Rios do Oeste & & & 100 & 100 & 100 & & & \\
\hline & Quatro Pontes & & & & 16,9 & 55,6 & & & 54 \\
\hline & Ubiratã & & & & & 10 & 10 & & \\
\hline & Total Geral & 2 & 2 & 5 & 5 & 6 & 5 & 4 & 3 \\
\hline
\end{tabular}

Fonte: elaborado a partir de PCS (2018b).

Observa-se que apenas duas cidades apresentam os dados uma com regularidade entre 2010 e 2016, Campinas e Santos do estado de São Paulo. Ainda assim, os percentuais atingidos pelos citados municípios de compras públicas sustentáveis não alcançam $1 \%$ do total das compras públicas a cada ano.

\section{Metodologia}

\section{Natureza da pesquisa}

Referente aos objetivos, a pesquisa é classificada como descritiva, decorrente da análise dos critérios de sustentabilidade presentes nos editais de licitação de municípios participantes do Programa Cidades Sustentáveis, por meio de uma técnica padronizada de coleta de dados (Gil, 2008). Já a sua natureza é quantitativa em decorrência do uso de um método de coleta de dados predeterminado com o objetivo de categoriza-los (Creswell, 2007).

Quanto às técnicas de coleta de dados, são utilizadas as tipologias de pesquisa bibliográfica e documental. A pesquisa bibliográfica é realizada para a compreensão do assunto estudado e para o desenvolvimento do método de coleta de dados, assim usam-se artigos científicos, livros, leis e documentos disponíveis na internet (Marconi \& Lakatos, 2011). A pesquisa documental é empregada para a coleta dos dados, a partir da análise de documentos públicos (Marconi \& Lakatos, 2011). Foram coletados editais de licitação dos municípios da amostra do estudo, através dos sites do portal da transparência de cada município.

Por fim, emprega-se o método de análise de conteúdo clássica (Bauer \& Gaskell, 2007), por meio da criação de categorias para a análise das informações extraídas dos editais de licitação.

\section{Procedimentos de coleta dos dados}

A população desta pesquisa é composta pelos munícipios brasileiros signatários do PCS que atendem a meta Compras Públicas Sustentáveis. Observou-se na consulta ocorrida em agosto de 2018 no site do PCS que apesar de haver dados disponíveis de 2010 a 2017 relativos ao atendimento da meta estudada na pesquisa, não existe uma regularidade nesse atendimento pelos municípios signatários do programa. Deste modo, 22 
cidades foram relacionadas pelo PCS como cumpridoras da meta CPS, sendo que nove cidades da relação não publicaram seus resultados e, dentre essas, só duas emitiram justificativa referente a não publicação.

A amostra da pesquisa consiste nos municípios que divulgaram até agosto de 2018, mês em que os dados foram coletados no site do PCS, dados da meta CPS referentes ao ano de 2017. A seleção do ano de 2017 como parâmetro ocorreu por ter sido o primeiro ano de mandato dos prefeitos que foram eleitos ou reeleitos nas eleições municipais de 2016. Dessa forma, dados os critérios estabelecidos, os municípios que compõem a amostra são: Guaíra/SP, Jaguariúna/SP e Quatro Pontes/PR.

A coleta dos editais de licitação é realizada nos portais da transparência municipais utilizando os seguintes filtros: a) editais publicados entre janeiro e setembro de 2018 (uma vez que os procedimentos estabelecidos pela nova gestão já estariam mais consolidados, pois esse período corresponde ao segundo ano de gestão do mandato iniciado em 2017); b) status das licitações abertas e encerradas dos editais publicados em 2018; c) modalidade de licitação de pregão. Outro filtro realizado na relação dos editais publicados é a exclusão daqueles destinados para obras de engenharia.

A escolha dos editais foi feita por sorteio sem reposição em planilha eletrônica. Os editais remanescentes foram enumerados de acordo com a ordem crescente da data de publicação. Selecionaram-se no total 43 editais, o que representa $20 \%$ dos editais publicados por cada cidade, no período pesquisado e considerando o filtro de seleção empregado. A quantidade final de editais selecionados não foi determinada por cálculo amostral, mas considerando a viabilidade de execução da pesquisa.

A coleta das informações dos editais é efetuada em duas etapas. A primeira com o auxílio do software NVIVO12 ${ }^{\circ}$ para verificação das palavras mais frequentes nos editais. O objeto dessa análise é contar todos os vocábulos presentes no texto a fim de identificar aqueles que remetessem aos critérios de sustentabilidade social e ambiental. A segunda etapa é executada com a leitura completa de todos os editais para realização da Análise de Conteúdo -AC-. Primeiramente, coletam-se as informações do número do edital para o controle das publicações analisadas, a cidade e a descrição do objeto licitado. Posteriormente, para identificar os critérios de sustentabilidade social e ambiental presentes nesses documentos, realiza-se a análise de conteúdo a partir da construção de um sistema de critérios sustentáveis de acordo com as referências pesquisadas. Essa coleta é efetivada também na pesquisa de termos chaves, com ferramentas de busca, de cada critério de sustentabilidade analisado. Busca-se contemplar nos valores das categorias todos os resultados possíveis para o atendimento do objetivo geral da pesquisa (Bauer \& Gaskell, 2007). O sistema desenvolvido é apresentado na tabela 2. A coleta e a análise dos dados coletados pela $\mathrm{AC}$ foram realizadas em uma planilha eletrônica.

TABELA 2

Sistema de critérios sustentáveis aplicado para coleta de dados nos editais

\begin{tabular}{|c|c|c|}
\hline Dimensão & Critério & Categoria \\
\hline \multirow{2}{*}{$\begin{array}{c}\text { Dados } \\
\text { Descritivos }\end{array}$} & Tipo de objeto & $\begin{array}{l}\text { 1. Bem } \\
\text { 2. Serviço não } \\
\text { engenharia }\end{array}$ \\
\hline & Tipo de licitação & $\begin{array}{l}\text { 1. Menor preço } \\
\text { 2. Melhor técnica } \\
\text { 3. Técnica e preço }\end{array}$ \\
\hline \multirow{9}{*}{$\begin{array}{l}\text { Sustentabilidade } \\
\text { Social }\end{array}$} & Parcelamento do objeto licitado em itens & $\begin{array}{l}\text { 0. Não parcelado } \\
\text { 1. Parcelado }\end{array}$ \\
\hline & $\begin{array}{l}\text { Produtos manufaturados e serviços nacionais que } \\
\text { atendam a normas técnicas brasileiras }\end{array}$ & \multirow{8}{*}{$\begin{array}{l}\text { 0. Não } \\
\text { 1. Sim } \\
\text { 2. Não aplicável }\end{array}$} \\
\hline & $\begin{array}{l}\text { Serviços prestados ou bens produzidos por empresas com } \\
\text { reserva de cargos para pessoa com deficiência ou } \\
\text { reabilitado da Previdência Social }\end{array}$ & \\
\hline & $\begin{array}{l}\text { Prazo de } 5 \text { dias úteis (prorrogável) para comprovação de } \\
\text { regularidade fiscal }\end{array}$ & \\
\hline & $\begin{array}{l}\text { Preferência na contratação de ME ou EPP em caso de } \\
\text { empate }\end{array}$ & \\
\hline & $\begin{array}{l}\text { Licitação exclusiva ou com estabelecimento de cota para } \\
\text { ME e EPP ou com prioridade de contratação de ME e } \\
\text { EPP locais }\end{array}$ & \\
\hline & Privilégio de ME e EPP locais nos critérios de desempate & \\
\hline & Alimentos orgânicos & \\
\hline & $\begin{array}{l}\text { Alimentos produzidos pela agricultura familiar local para } \\
\text { escolas municipais. }\end{array}$ & \\
\hline
\end{tabular}

Fonte: elaborado a partir de Alencastro et al. (2014), Lei 8.666/93, Lei

Complementar 123/2006, Instrução Normativa N N $^{\mathrm{O}}$ 01/2010, Santos Neto (2017). 
TABELA 2

Sistema de critérios sustentáveis aplicado para coleta de dados nos editais

\begin{tabular}{|c|c|c|}
\hline Dimensão & Critério & Categoria \\
\hline \multirow{12}{*}{$\begin{array}{c}\text { Sustentabilidade } \\
\text { Ambiental }\end{array}$} & $\begin{array}{l}\text { Bens constituidos, no todo ou em parte, por material } \\
\text { reciclado, atóxico, biodegradável, conforme normas ABNT } \\
\text { NBR }-15448-1 \text { e } 15448-2 \text {. }\end{array}$ & $\begin{array}{l}\text { 0. Não } \\
\text { 1. Sim } \\
\text { 2. Não aplicável }\end{array}$ \\
\hline & $\begin{array}{l}\text { Bens certificados pelo Instituto Nacional de Metrologia, } \\
\text { Normalizaçãoe Qualidade Industrial (Inmetro) como } \\
\text { produtos sustentáveis. }\end{array}$ & \multirow{11}{*}{$\begin{array}{l}\text { 0. Não } \\
\text { 1. Sim } \\
\text { 2. Não aplicável }\end{array}$} \\
\hline & $\begin{array}{l}\text { Bens, preferencialmente, acondicionados em embalagem } \\
\text { individual e de materiais recicláveis, com o menor volume e } \\
\text { garantindo proteção. }\end{array}$ & \\
\hline & $\begin{array}{l}\text { Equipamentos eletroelettônicos (EEE) sem substâncias } \\
\text { perigosas em concentração acima da recomendada pela } \\
\text { Restriction of Certain Hazardous Substances (RoHS). }\end{array}$ & \\
\hline & $\begin{array}{l}\text { Critérios de preferência para propostas que propiciem maior } \\
\text { economia de energia, água, recursos naturais e redução da } \\
\text { emissão de gases poluentes e residuos. }\end{array}$ & \\
\hline & Especificação do tratamento correto de resíduos ou rejeitos. & \\
\hline & Exige-se a aquisição de materiais com maior durabilidade. & \\
\hline & $\begin{array}{l}\text { Exige-se a comprovação de origem legal e nãopredatória de } \\
\text { itens feitos ou derivados da madeira. }\end{array}$ & \\
\hline & $\begin{array}{l}\text { Preferência por etanol como combustivel na contratação de } \\
\text { serviços de frota. }\end{array}$ & \\
\hline & $\begin{array}{l}\text { Preferência por aquisição de veiculos eficientes quanto a } \\
\text { redução da poluição e ao tipo de combustivel. }\end{array}$ & \\
\hline & $\begin{array}{l}\text { Empresa de serviços de frota deve ter politica de logistica } \\
\text { reversa ou de responsabilidade compartilhada para o } \\
\text { descarte de peças. }\end{array}$ & \\
\hline & $\begin{array}{l}\text { Utilizar materiais com baixo consumo energético nos } \\
\text { serviços de vigilância. }\end{array}$ & \\
\hline
\end{tabular}

Fonte: elaborado a partir de Alencastro et al. (2014), Lei 8.666/93, Lei

Complementar 123/2006, Instrução Normativa No 01/2010, Santos Neto (2017).

\section{Procedimentos de análise dos dados}

Nesta pesquisa, os editais analisados foram os referentes às aquisições de bens e prestação de serviços não relacionados a obras de engenharia. Optou-se por essa abordagem pelo fato de que as especificações dos editais relativos a obras e serviços de engenharia devem atender às normas técnicas específicas da área (Santos Neto, 2017). Nesse sentido, para não comprometer a análise dos dados, preferiu-se não considerar esse tipo de edital.

A análise inicial dos dados é realizada com a identificação das palavras mais frequentes dos editais de licitação pública de cada município participante da amostra. O intuito da análise é identificar vocábulos em destaque que remetam aos critérios de sustentabilidade ambiental e/ou social. Portanto, é gerada uma nuvem de palavras do conjunto dos editais selecionados para cada cidade.

Posteriormente, inicia-se a leitura completa dos editais para realização da AC. Primeiro, analisa-se a descrição do objeto de licitação para determinar se o edital é para aquisição de bem ou contratação de serviço. Nessa revisão busca-se também por termos que remetam à sustentabilidade de forma explícita ou implícita, por vezes sendo necessária a consulta em outras fontes. Com isso, é possível identificar os códigos da AC a serem aplicados ao respectivo edital, uma vez que alguns códigos se consideram aplicáveis só para determinados objetos de licitação. Os casos sinalizados com o valor Não Aplicável referem-se às situações em que não é possível observar o código analisado no edital por não se aplicar ao tipo de objeto licitado. Tal conduta é tomada para que a codificação desenvolvida contemple todos os casos possíveis (Bauer \& Gaskell, 2007).

Por último, os dados coletados pela AC foram sistematizados de forma quantitativa-categórica, sendo analisados a partir da quantidade identificada da presença, ausência ou não aplicação dos códigos da $\mathrm{AC}$ em cada edital. Nos casos aplicáveis, são apresentadas na análise dos resultados. Além disso, a análise é feita de forma agregada para todos os editais, sem realizar distinção dos dados de cada município participante da amostra da pesquisa. 


\section{Principais limitações da pesquisa}

A principal limitação foi a quantidade de cidades analisadas, em decorrência da não regularidade da publicação dos resultados da meta estudada pelos municípios participantes do programa para o ano base da pesquisa. Outro ponto foi a dificuldade de identificação na coleta de dados de alguns critérios sociais e ambientais nos editais. Esses critérios estão relacionados a objetos de licitação mais específicos. Assim, como não foi aplicada uma restrição aos tipos de objeto (com exceção às obras de engenharia), resultou na seleção de editais com uma maior variabilidade relativa às características dos objetos.

\section{Análise e discussão dos resultados}

\section{Descrição dos munícipios e respectivos editais analisados}

Os municípios participantes da pesquisa foram Guaíra (SP), Jaguariúna (SP) e Quatro Pontes (PR). Essas cidades são consideradas de pequeno porte quanto ao tamanho populacional. De acordo com o último Censo realizado em 2010, Guaíra tem 37.404 habitantes, Jaguariúna tem 44.311 e Quatro Pontes tem 3.803 (IBGE, 2020). O Índice de Desenvolvimento Humano (IDHM) em 2010 dessas cidades é situado na faixa de desenvolvimento humano alto (Guaíra - 0,753; Jaguariúna - 0,784 e Quatro Pontes - 0,791). Além de que os três municípios também têm as mesmas dimensões que contribuem para o IDHM alto: longevidade, renda e educação (PNUD et al., 2020).

Referente aos editais, foram analisados um total de 43, sendo 12 publicados pela cidade de Guaíra (SP), 22 de Jaguariúna (SP) e 9 de Quatro Pontes (PR). Todos os editais utilizaram o pregão como modalidade de licitação e, consequentemente, apresentam o critério do menor preço para julgamento e seleção das propostas, conforme preceito legal (Lei $\left.\mathrm{N}^{\circ} 10.520 / 2002\right)$. Quanto aos itens licitados, 30 editais tinham como objeto a aquisição de bens de consumo e 13, a prestação de serviços não relacionados à engenharia.

Nas Figuras 1, 2, 3 são apresentadas as nuvens de palavras extraídas dos editais de licitação de cada cidade.

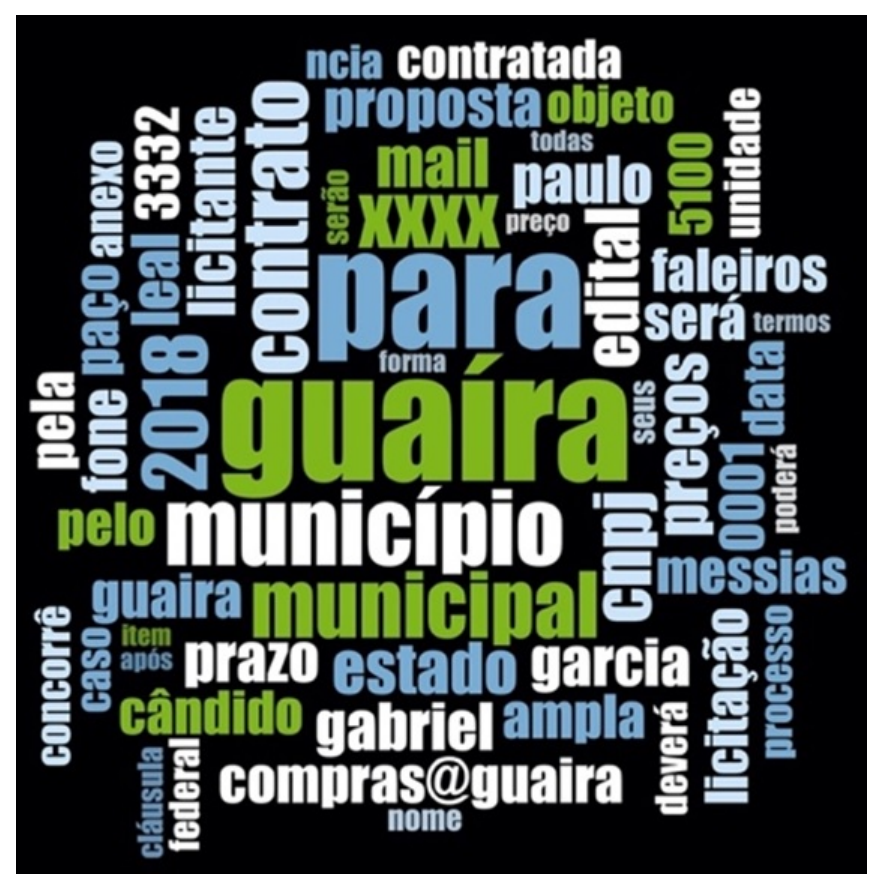

FIGURA 1

Frequência de palavras - Guaíra

Fonte: dados da pesquisa, 2019. 


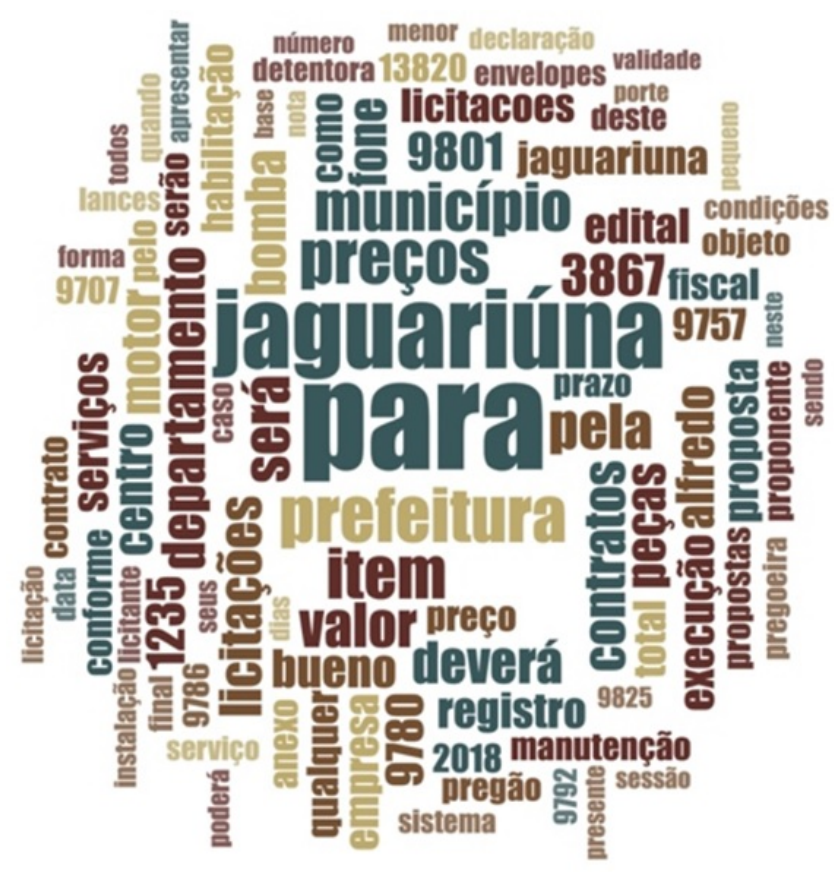

FIGURA 2

Frequência de palavras - Jaguariúna Fonte: dados da pesquisa, 2019.

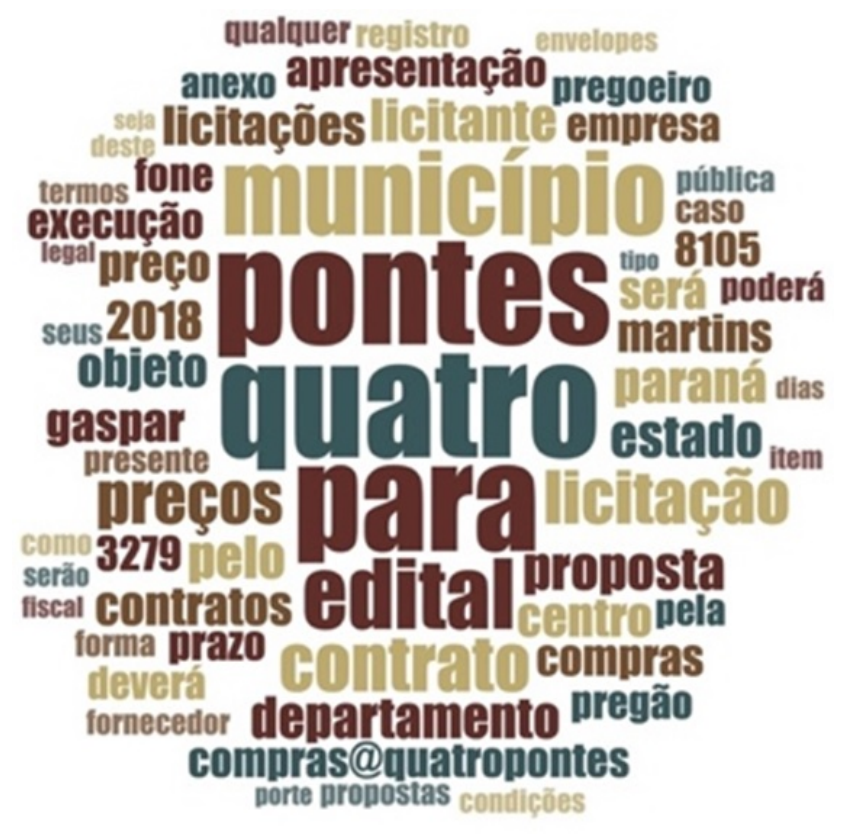

FIGURA 3

Frequência de palavras - Quatro Pontes Fonte: dados da pesquisa, 2019. 
A evidência encontrada nas nuvens de palavras sugere que nenhum termo relacionado à sustentabilidade foi mencionado com grande frequência nos editais analisados. Os vocábulos com maior frequência nos editais referem-se aos nomes das respectivas cidades e às etapas do processo de licitação, como os termos: "edital”, "preço", "proposta”, "objeto", "prazo", “contrato", "fornecedor”, "licitação”.

\section{Critérios de sustentabilidade social}

Ao realizar a análise dos editais, pesquisou-se sobre a presença de nove critérios de sustentabilidade social que foram representados pelos códigos da Análise de Conteúdo. Na tabela 3 apresenta-se, sumariamente, a quantidade de editais nos que critérios sociais estão presentes, ausentes ou os casos não aplicáveis.

Dois dos nove critérios listados (códigos 1 e 2) eram de aplicação facultativa pela gestão municipal, uma vez que poderia ser concedida, no edital, margem de preferência aos produtos e serviços que atendessem a tais condições. Os critérios correspondentes aos códigos de 3 a 7 são aplicados para promover estratégias de desenvolvimento local ao facilitarem a participação de Microempresas -ME- e Empresas de Pequeno Porte -EPP-. Por fim, a presença dos critérios 8 e 9 está condicionada ao tipo do objeto licitado, já que se referem à compra de alimentos. Esses últimos parâmetros são relacionados ao aspecto social, pela possibilidade de promover o desenvolvimento local a partir da inclusão socioeconômica dos agricultores locais e incentivar a alimentação saudável.

TABELA 3

Critérios de Sustentabilidade Social Pesquisados nos Editais de Licitação

\begin{tabular}{|c|c|c|c|c|}
\hline Código & Critério & Presente & Ausente & $\begin{array}{c}\text { Não } \\
\text { Aplicável }\end{array}$ \\
\hline 1 & $\begin{array}{l}\text { Produtos manufaturados e serviços nacionais que } \\
\text { atendam a normas técnicas brasileiras }\end{array}$ & 0 & 43 & 0 \\
\hline 2 & $\begin{array}{l}\text { Serviços prestados ou bens produzidos por } \\
\text { empresas com reserva de cargos para pessoa com } \\
\text { deficiência ou reabilitado da Previdência Social }\end{array}$ & 0 & 43 & 0 \\
\hline 3 & Parcelamento do objeto licitado em itens & 16 & 27 & 0 \\
\hline 4 & $\begin{array}{l}\text { Prazo de } 5 \text { dias úteis (prorrogável) para } \\
\text { comprovação de regularidade fiscal }\end{array}$ & 40 & 3 & 0 \\
\hline 5 & $\begin{array}{l}\text { Preferência na contratação de ME ou EPP em caso } \\
\text { de empate }\end{array}$ & 27 & 1 & 15 \\
\hline 6 & $\begin{array}{l}\text { Licitação exclusiva ou com estabelecimento de cota } \\
\text { para ME e EPP ou com prioridade de contratação de } \\
\text { ME e EPP locais }\end{array}$ & 22 & 21 & 0 \\
\hline 7 & $\begin{array}{l}\text { Privilégio de ME e EPP locais nos critérios de } \\
\text { desempate }\end{array}$ & 0 & 43 & 0 \\
\hline 8 & Alimentos orgânicos & 0 & 6 & 37 \\
\hline 9 & $\begin{array}{l}\text { Alimentos produzidos pela agricultura familiarlocal } \\
\text { para escolas municipais. }\end{array}$ & 1 & 2 & 40 \\
\hline
\end{tabular}

Fonte: dados da pesquisa, 2019. 
Ao buscar critérios de sustentabilidade social nos editais, percebe-se que a presença da maior parte deles (códigos 3, 4, 5 e 6) é decorrente da exigência legal. Esses critérios são os recursos presentes na Lei Complementar $\mathrm{N}^{\circ} 123 / 2006$ atualizada, os quais visam promover o desenvolvimento das ME e EPP por meio de uma política pública afirmativa de acesso ao mercado por artifício das aquisições públicas. Chama a atenção por não ser apresentado em três editais o critério de código 4 . O prazo especificado nesses editais foi de dois dias úteis, no entanto, esse prazo era fornecido antes da atualização da Lei Complementar No 123 em 2013. Tal fato pode corresponder a um indício de que os editais não foram elaborados de acordo com a legislação vigente à época. O código 7 foi o único recurso da referida lei não identificado nos editais, no caso do município de Quatro Pontes/PR há uma mensagem explícita sobre o não favorecimento de vantagem no desempate às empresas locais. Não acontece igual com os municípios de São Paulo.

Para os critérios cuja adoção requer uma avaliação do gestor público, como os de códigos 1, 2, 8 e 9, verificase que, praticamente, não há consideração. Esses resultados são convergentes com os encontrados por Tadielo (2016), em um estudo realizado com funcionários públicos do setor de compras de nove municípios do Rio Grande do Sul. Esse autor identificou que os fatores que mais contribuem para a realização de editais de licitação com critérios sustentáveis são a atuação de órgãos fiscalizadores e as determinações legais. Por outro lado, os fatores que menos contribuem para as CPS são a falta de conhecimento, elevação dos custos, preços e capacidade técnica dos servidores.

Já em relação aos códigos 8 e 9, referentes à aquisição de alimentos, o resultado para os casos aplicáveis foi a não presença desses critérios nos editais. Quanto ao critério de código 8, uma interpretação possível sobre esse resultado é que a população tem a percepção de que esses alimentos são mais caros do que os não orgânicos, inibindo o seu consumo (Ribeiro, 2017). Essa evidência ainda é identificada no estudo de Carvalho e Sousa (2013), na aquisição de alimentos para um restaurante universitário da Universidade Federal do Piauí. Os autores detectaram na pesquisa, que esses compradores públicos também acreditam que os fornecedores locais não têm a capacidade de atendimento da demanda do restaurante nem a estrutura administrativa para cumprirem as exigências legais necessárias para a habilitação às disputas nos pregões eletrônicos. Por isso, esses gestores acreditam que utilizar o pregão eletrônico como política de compra é um fator limitante para comprar dos pequenos produtores e cooperativas de alimentos orgânicos locais (Carvalho \& Sousa, 2013).

\section{Critérios de Sustentabilidade Ambiental}

$\mathrm{Na}$ tabela 4 são apresentados os critérios de sustentabilidade ambiental pesquisados nos editais de licitação dos municípios participantes da pesquisa. Esses parâmetros utilizados estão diretamente relacionados ao tipo de objeto licitado, sendo alguns critérios aplicáveis à avaliação dos bens e outros determinantes das prestações de serviço. Com isso, observa-se a maior diversidade de critérios ambientais (Igarashi et al., 2015), bem como uma expressiva quantidade de editais em que não é possível identificar a aplicação do critério ambiental em questão. Para os casos aplicáveis, percebe-se uma baixa presença em todos os critérios ambientais elencados na pesquisa. 
TABELA 4

Critérios de Sustentabilidade Ambiental Pesquisados nos Editais de Licitação

\begin{tabular}{|c|c|c|c|c|}
\hline Código & Critério Ambiental & Presente & Ausente & $\begin{array}{c}\text { Não } \\
\text { Aplicável }\end{array}$ \\
\hline 1 & $\begin{array}{l}\text { Bens constituidos, no todo ou em parte, por material } \\
\text { reciclado, atóxico, biodegradável, conforme normas } \\
\text { ABNT NBR - 15448-1 e 15448-2. }\end{array}$ & 3 & 21 & 19 \\
\hline 2 & $\begin{array}{l}\text { Bens certificados pelo Instituto Nacional de } \\
\text { Metrologia, Normalização e Qualidade Industrial } \\
\text { (Inmetro) como produtos sustentáveis. }\end{array}$ & 2 & 25 & 16 \\
\hline 3 & $\begin{array}{l}\text { Bens, preferencialmente, acondicionados em } \\
\text { embalagem individual e de materiais recidáveis, com o } \\
\text { menor volume e garantindo proteção. }\end{array}$ & 6 & 22 & 15 \\
\hline 4 & $\begin{array}{l}\text { Equipamentos eletroeletrônicos (EEE) sem substâncias } \\
\text { perigosas em concentração acima da recomendada pela } \\
\text { Restriction of Certain Hazardous Substances (RoHS). }\end{array}$ & 0 & 6 & 37 \\
\hline 5 & $\begin{array}{l}\text { Critérios de preferência para propostas que propiciem } \\
\text { maior economia de energia, água, recursos naturais e } \\
\text { redução da emissão de gases poluentes e residuos. }\end{array}$ & 1 & 30 & 12 \\
\hline 6 & $\begin{array}{l}\text { Especificação do tratamento correto de residuos ou } \\
\text { rejeitos. }\end{array}$ & 2 & 16 & 25 \\
\hline 7 & $\begin{array}{l}\text { Exige-se a aquisição de materiais com maior } \\
\text { durabilidade. }\end{array}$ & 6 & 14 & 23 \\
\hline 8 & $\begin{array}{l}\text { Exige-se a comprovação de origem legal e não } \\
\text { predatória de itens feitos ou derivados da madeira. }\end{array}$ & 0 & 6 & 37 \\
\hline 9 & $\begin{array}{l}\text { Preferência por etanol como combustivel na } \\
\text { contratação de serviços de frota. }\end{array}$ & 1 & 2 & 40 \\
\hline 10 & $\begin{array}{l}\text { Preferência por aquisição de veiculos eficientes quanto } \\
\text { a redução da poluiçãoe ao tipo de combustivel. }\end{array}$ & 1 & 2 & 40 \\
\hline 11 & $\begin{array}{l}\text { Empresa de serviços de frota deve ter politica de } \\
\text { logistica reversa ou de responsabilidade compartilhada } \\
\text { para o descarte de peças. }\end{array}$ & 0 & 1 & 42 \\
\hline 12 & $\begin{array}{l}\text { Utilizar materiais com baixo consumo energéticonos } \\
\text { serviços de vigilância. }\end{array}$ & 0 & 1 & 42 \\
\hline
\end{tabular}

Fonte: dados da pesquisa, 2019.

Os critérios ambientais aplicados nessa pesquisa foram desenvolvidos, principalmente, à luz da instrução Normativa $\mathrm{N}^{\circ} 01 / 2010$. Ao realizar a busca textual nos editais desses critérios, verificou-se que os mesmos não são facilmente encontrados. Não há uma seção específica no edital de licitação com a consideração dos critérios de sustentabilidade empregados. Além disso, nem sempre é fácil identificá-los por meio da pesquisa textual baseada no rastreio de termos que remetam à sustentabilidade. Essa evidência também está presente no trabalho de Gallon et al. (2019), apesar de ter sido realizado em uma universidade pública federal. Um exemplo nesta pesquisa é referente à análise para verificação do atendimento ao critério de código 1 . As normas da ABNT mencionadas no critério retratam a terminologia dos bens e a compostabilidade de embalagens plásticas, respectivamente. Não foi possível constatar nos editais exigências detalhadas sobre tais aspectos. Portanto, só foram considerados como casos aplicáveis aqueles nos quais foi possível identificar as palavras chaves "material reciclado", "atóxico", "biodegradável”, ou itens que claramente são relacionados com essas características: embalagem de papel, papelão, etc.

Em adição a isso, para avaliar se determinados critérios ambientais são aplicáveis ao objeto presente no edital se fez necessário realizar pesquisas em outras fontes. Percebe-se nesses casos que os critérios estão implícitos e não é possível discernir se as especificações dispostas tinham a intenção clara de considerar um critério sustentável (Igarashi et al., 2015). Tal fato é verificado na análise do critério de código 7. Essa identificação só ocorreu após uma análise aprofundada, na qual em um dos casos, a licitação para aquisição de caixa de descarga, foi necessário realizar a consulta das especificações técnicas do produto em outra fonte que não era a instrução normativa. No edital foi especificado para esse objeto o padrão CIPLA de qualidade igual ou 
superior. Apesar de a descrição expor que a requisição é referente a um padrão de qualidade, não é especificado o atributo da qualidade que o comprador público almeja com essa exigência. Nesse caso, considerou-se que houve o atendimento ao critério do código 7, porque o padrão CIPLA se refere a um produto de longa vida útil.

\section{Aspectos gerais na avaliação dos editais}

A percepção obtida por meio da leitura e análise dos editais publicados pelos três municípios estudados é a de que a presença de critérios de sustentabilidade ocorre por causa das determinações legais. Isso é evidenciado pelo fato de a maior incidência de critérios sustentáveis serem os sociais e relacionados às regras diferenciadas para as microempresas e empresas de pequeno porte. Enquanto que para identificar os critérios ambientais se faz necessário expor os requisitos de forma mais clara, o que nem sempre é feito.

Em virtude dessa situação, não é possível avaliar se os critérios contemplados nos editais analisados partem de uma ação voluntária da gestão municipal, ainda que esse seja o comportamento esperado. Esperase tal conduta pelo fato de os municípios aderirem voluntariamente à meta de CPS no Projeto Cidades Sustentáveis e reportarem que a cumprem. A análise dos editais realizada nesse trabalho não foi estruturada de forma que possibilite a extrapolação para os demais editais publicados pelas prefeituras. Nesse sentido, reconhece-se a limitação da pesquisa. Porém, as evidências encontradas até o momento permitem sugerir que a gestão municipal invista em planejamento estratégico e treinamento da equipe considerando os requisitos necessários para uma gestão sustentável do processo de compras. Dessa forma, é possível estabelecer critérios claros para conduzir a gestão sustentável por meio das CPS. Além disso, as estratégias sugeridas possibilitarão aos funcionários públicos a terem maior domínio sobre como considerar esses critérios no processo licitatório (Pacheco-Blanco \& Bastante-Ceca, 2016; Tadielo, 2016).

\section{Conclusão}

O objetivo da pesquisa foi identificar critérios de sustentabilidade social e ambiental em editais de licitação de três municípios participantes do Projeto Cidades Sustentáveis e adotantes da meta "Compras Públicas Sustentáveis". Foram identificados pelo menos cinco critérios de sustentabilidade social e oito critérios de sustentabilidade ambiental nos 43 editais analisados. Esse resultado não implica dizer que todos os editais apresentaram, concomitantemente, todos os critérios sociais e ambientais identificados nesse trabalho. Observa-se tal fato em decorrência das particularidades de cada objeto de licitação, uma vez que há critérios de sustentabilidade que são específicos a bens de consumo e não se aplicam à prestação de serviço.

A estratégia metodológica aplicada foi estruturada em duas etapas. A primeira foi a verificação da frequência dos vocábulos presentes em todos os editais de cada município estudado. Com isso, objetivou-se identificar se haviam termos de sustentabilidade que se destacassem nos editais. Porém, os resultados desta análise não evidenciaram nenhuma palavra diretamente relacionada à sustentabilidade em grande frequência no conjunto de editais correspondente a cada município. A segunda etapa realizada foi a busca pelos parâmetros por cada tipo (social e ambiental). Para tanto, aplicou-se a Análise de Conteúdo, desenvolvendose uma estrutura de codificação após realizar uma a pesquisa bibliográfica. Com esta etapa concluída, foi iniciada a pesquisa documental tendo como objeto de análise os editais de licitação e como o propósito determinar a presença de critérios de sustentabilidade nesses documentos.

A contribuição da pesquisa está alicerçada em trazer evidências sobre as práticas sustentáveis relativas às compras públicas em municípios de pequeno porte e voluntariamente participantes do Projeto Cidades Sustentáveis. Apesar do projeto existir desde 2012, no momento de realizar a pesquisa bibliográfica não foram encontrados outros estudos sobre as CPS nas cidades participantes. Identificaram-se semelhanças nesse estudo 
em relação aos outros, quanto à adoção de critérios nas CPS. Dessa forma, foi possível estabelecer paralelos com os critérios utilizados em outros órgãos públicos de estados e esferas distintos. As evidências desses estudos também mostram que os critérios mais encontrados são aqueles determinados legalmente e que há a necessidade de investir no treinamento dos servidores públicos para que seja possível ampliar a consideração dos referidos critérios nas CPS.

Por fim, nota-se que a composição da amostra da pesquisa foi um fator limitante, uma vez que inviabilizou a identificação de se mais cidades participantes do programa utilizam a mesma estrutura de critérios sustentáveis nos seus editais. Adicionalmente, a não restrição dos objetos de licitação impossibilitou identificar com maior uniformidade os parâmetros sustentáveis presentes. Portanto, sugere-se que essas limitações possam ser direcionadoras em pesquisas futuras com o objetivo de aprofundar a análise dos dados, buscando reconhecer variáveis que possam estar correlacionadas com as CPS nos municípios participantes do projeto.

\section{Referencias}

Alarcão, A. L. L., Tupinambá, D. D., Stefani, E. de, Matsuura, M. I. da S. F., Silva, N. C. da, \& Menezes, R. A. de L. (2018). Compras sustentáveis. In Consumo e produção responsáveis: Contribuições da Embrapa (pp. 93-110). Embrapa. http://www.alice.cnptia.embrapa.br/alice/handle/doc/1104011

Alencastro, M. A. C., Silva, E. V. da, \& Lopes, A. M. D. (2014). Contratações sustentáveis na administração pública brasileira: A experiência do Poder Executivo federal. Revista de Administração Pública, 48(1), 207-235. https:/ /doi.org/10.1590/S0034-76122014000100009

Bauer, M. W., \& Gaskell, G. (2007). Pesquisa qualitativa com texto, imagem e som: Um manualprático, 6a ed. Petrópolis: Vozes.

Biderman, R., Macedo, L. S. V. de, Neto, M., Prestes, M., \& Mazon, R. (2008). Guia de compras públicas sustentáveis: Uso do poder de compra do governo para a promoção do desenvolvimento sustentável (FGV EAESP - GVces Relatórios Técnicos). Centro de Estudos em Sustentabilidade (FGVces). http://hdl.handle.net/10438/15417

Brasil, M. da E. (2020, julho 31). Catálogo de Materiais (CATMAT) e Serviços (CATSER). Comprasnet - Ministério da Economia. https://siasgnet-consultas.siasgnet.estaleiro.serpro.gov.br/siasgnet-catalogo/\#/

Brasil, M. do M. A. (2020, julho 31). Agenda Ambiental na Administração Pública-A3P. http://a3p.mma.gov.br

Brasil, T. de C. da U. (2010). Licitações e contratos: Orientações e jurisprudência do TCU (Tribunal de Contas da União) TCU, S.-G. da P. S. Federal, \& S. E. de E. e Publicações, Orgs.; 4. ed.

Bratt, C., Hallstedt, S., Robèrt, K. H., Broman, G., \& Oldmark, J. (2013). Assessment of criteria development for public procurement from a strategic sustainability perspective. Journal of Cleaner Production, 52, 309-316. https://do i.org/10.1016/j.jclepro.2013.02.007

Carvalho, D. B. de, \& Sousa, E. D. S. (2013). Agenda ambiental da administração pública (A3P) elicitações sustentáveis: um estudo no restaurante universitário da Universidade Federal do Piaui. Anais dos Colóquios Internacionais sobre Gestão Universitária. XIII Colóquio Internacional sobre Gestão Universitária nas Américas, Florianópolis. https://repositorio.ufsc.br/handle/123456789/114753

Creswell, J. W. (2007). Projeto de Pesquisa: Métodos qualitativo, quantitativo e misto, 2. ed. Porto Alegre: Artmed.

EC, E. C. (2016). Buying Green! A Handbook on Green Public Procurement, 3a ed. Publications Office of the European Union. http://ec.europa.eu/environment/gpp/pdf/Buying-Green-Handbook-3rd-Edition.pdf

EC, E. C. (2018). GPP Criteria - Background and Approach. European Commission Environment. https://ec.euro pa.eu/environment/gpp/gpp_criteria_en.htm

Fernandes, A. L., \& de Oliveira, A. G. (2015). Compras na Administração Pública: O Pregão Eletrônico como Instrumento de Eficiência diante das Modalidades da Lei no 8.666/93. Revista Controle - Doutrina e Artigos, 13(1), 262-283. https://doi.org/10.32586/rcda.v13i1.31 
Gallon, I., Flores, G. M., Trevisan, M., \& Kneipp, J. M. (2019). Análise dos critérios de sustentabilidade aplicados nas licitações de uma universidade pública federal. Revista de Gestão Ambiental e Sustentabilidade - GeAS, .(2), 315-334. https://doi.org/10.5585/geas.v8i2.1211

Gelderman, C. J., Ghijsen, P. W. Th., \& Brugman, M. J. (2006). Public procurement and EU tendering directives explaining non-compliance. International Journal of Public Sector Management, 19(7), 702-714. https://doi.or $\mathrm{g} / 10.1108 / 09513550610704716$

Gil, A. C. (2008). Métodos e Técnicas de Pesquisa Social, 6. ed. Cidade: Atlas.

Gomes, D., \& Zambam, N. J. (2011). O Desafio da Sustentabilidade Urbana. Revista Brasileira de Direito, 7(1), 39-60. https://doi.org/10.18256/2238-0604/revistadedireito.v7n1p39-60

Grandia, J. (2016). Finding the missing link: Examining the mediating role of sustainable public procurement behaviour.Journal of Cleaner Production, 124, 183-190. https://doi.org/10.1016/j.jclepro.2016.02.102

IBGE, I. B. de G. e E. (2020, julho 31). Conheça Cidades e Estados do Brasil [Governamental]. Instituto Brasileiro de Geografia e Estatística. https://cidades.ibge.gov.br

Igarashi, M., de Boer, L., \& Michelsen, O. (2015). Investigating the anatomy of supplier selection in green public procurement. Journal of Cleaner Production, 108, 442-450. https://doi.org/10.1016/j.jclepro.2015.08.010

Instrução Normativa No 01/2010, (2010) (testimony of Brasil). https://www.governodigital.gov.br/documentos-earquivos/legislacao/INSTRUCAO NORMATIVA N. 01 de 2010 - Compras Sustentav.pdf/view

Lei Complementar No 123/2006, Diário Oficial da União (DOU) (2006) (testimony of Brasil). http://www.planal to.gov.br/ccivil_03/leis/lcp/lcp123.htm

Lei $N^{\circ} 10.520 / 2002$, Diário Oficial da União (DOU) (2002) (testimony of Brasil). http://www.planalto.gov.br/cci vil_03/LEIS/2002/L10520.htm

Lei N 8.666/93, Diário Oficial da União (DOU) (1993) (testimony of Brasil). http://www.planalto.gov.br/ccivil_ 03/leis/18666cons.htm

Majerník, M., Daneshjo, N., Chovancová, J., \& Sančiová, G. (2017a). Modelling the Process of Green Public Procurement. TEM Journal, 6(2), 272-278. https://doi.org/DOI: 10.18421/TEM62-12

Marconi, M. de A., \& Lakatos, E. M. (2011). Técnicas de Pesquisa: Planejamento e execução de pesquisas, amostragens e técnicas de pesquisa, elaboração, análise e interpretação de dados, 7o ed. São Paulo: Atlas.

Oliveira, B. C. S. C. M. de, \& Luzio dos Santos, L. M. (2015). Compras públicas como política para o desenvolvimento sustentável. Revista de Administração Pública - RAP, 49(1), 189-206. http://dx.doi.org/10.1590/0034-761218 33

Pacheco-Blanco, B., \& Bastante-Ceca, M. J. (2016). Green public procurement as an initiative for sustainable consumption. An exploratory study of Spanish public universities. Journal of Cleaner Production, 133, 648-656. https://doi.org/10.1016/j.jclepro.2016.05.056

PCS, P. C. S. (2017). Relatório Anual Programa Cidades Sustentáveis - Anos 2015 e 2016 [Relatório Anual]. Programa Cidades Sustentáveis. http://www.cidadessustentaveis.org.br

PCS, P. C. S. (2018a). Eixo: Gestão Local Para a Sustentabilidade. Programa Cidades Sustentáveis. https://www.cid adessustentaveis.org.br

PCS, P. C. S. (2018b). Indicador: Compras Públicas Sustentáveis. Programa Cidades Sustentáveis. https://www.cida dessustentaveis.org.br

PCS, P. C. S. (2018c). Lista completa dos prefeitos (as) eleitos (as) nas eleições municipais de 2016 e partidos políticos que assinaram a carta-compromisso do Programa Cidades Sustentáveis. Programa Cidades Sustentáveis. https:/ /www.cidadessustentaveis.org.br

PCS, P. C. S. (2019a). Programa Cidades Sustentáveis - Institucional - Como Aderir. Programa Cidades Sustentáveis. https://www.cidadessustentaveis.org.br/institucional/pagina/como-aderir

PCS, P. C. S. (2019b). Programa Cidades Sustentáveis - Institucional - PCS. Programa Cidades Sustentáveis. https:/ /www.cidadessustentaveis.org.br/institucional/pagina/pcs 
PNUD, P. das N. U. para o D., Ipea, I. de P. E. A., \& FJP, F. J. P. (2020, julho 31). Consulte o perfil da sua localidade. Atlas do Desenvolvimento Humano no Brasil. http://www.atlasbrasil.org.br/2013/pt/

Reis, L. E., \& Backes, C. (2015). A licitação pública e sua finalidade de promover o desenvolvimento nacional sustentável. Revista de Estudos Jurídicos UNESP, 19(30). http://dx.doi.org/10.22171/rej.v19i30.1590

Ribeiro, C. G., \& Inácio Júnior, E. (2014). Mensurando o mercado de compras governamentais brasileiro. Cadernos de Finanças Públicas, 14, 265-287. http://repositorio.enap.gov.br/handle/1/3816

Ribeiro, C. G., \& Inácio Júnior, E. (2019). O Mercado de Compras Governamentais Brasileiro, 2006-2017: Mensuração e análise. IPEA. https://www.ipea.gov.br/portal/images/stories/PDFs/TDs/td_2476_sumex.pdf

RNSP, R. N. S. P., Ethos, I., \& PCS, P. C. S. (2012). Programa Cidades Sustentáveis (p. 32) [Apresentação]. Rede Nossa São Paulo - RNSP. https://doi.org/https://www.cidadessustentaveis.org.br

Santos Neto, A. M. V. dos. (2017). Compras Sustentáveis Municipais. Serviço Brasileiro de Apoio às Micro e Pequenas Empresas - Sebrae. http://www.sebrae.com.br

Silva, R. C. da, \& Barki, T. V. P. (2014). Compras públicas compartilhadas: A prática das licitações sustentáveis. Revista do Serviço Público, 63(2), 157-175. https://doi.org/10.21874/rsp.v63i2.93

Souza, T. F. de, Quelhas, O. L. G., \& Gomes, C. F. S. (2015). Contratações Públicas Sustentáveis: Uma Análise do Perfil das Licitações de Instituições Públicas Brasileiras. Revista Eletrônica em Gestão, Educação e Tecnologia Ambiental, 19(2), 477-492. https://doi.org/105902/2236117016757

Tadielo, L. E. (2016). Licitações públicas sustentáveis: Um estudo sobre os municípios do Vale do Jaguari, Trabalho de Conclusão de Curso de Especialização, Universidade Federal de Santa Maria. http://repositorio.ufsm.br/ha ndle/1/11277

Testa, F., Annunziata, E., Iraldo, F., \& Frey, M. (2016). Drawbacks and opportunities of green public procurement: An effective tool for sustainable production. Journal of Cleaner Production, 112, 1893-1900. https://doi.org/10.10 16/j.jclepro.2014.09.092

\section{Notas}

* $\quad$ Artigo de investigação.

\section{Licencia Creative Commons CC BY 4.0}

Para citar este artigo: Lemos, L. V., Rodrigues, R. N., Lagioia, U.C.T., \& Libonati, J. J. (2020). Compras públicas sustentáveis: Uma análise dos editais de licitação de cidades brasileiras participantes do Programa Cidades Sustentáveis. Cuadernos de Contabilidad, 21. https://doi.org/10.11144/Javeriana.cc21.cpsa 